\title{
RELATIONSHIP BETWEEN THE KNEE AND HINDFOOT AXES IN PATIENTS WITH SEVERE KNEE OSTEOARTHRITIS
}

\section{RELAÇÃO ENTRE O EIXO ANATÔMICO DO JOELHO E O EIXO DO RETROPÉ EM PACIENTES COM GONARTROSE AVANÇADA}

\author{
Henrique Mansur ${ }^{1,2}$ (i), Felipe almeida Rocha ${ }^{1}$ (i), Pedro Guilme Teixeira de Sousa Filho ${ }^{1}$ (i), \\ ISNAR MOREIRA DE CASTRO JUNIOR ${ }^{1}$ (1)
}

1. Instituto Nacional de Traumatologia e Ortopedia, Rio de Janeiro, RJ, Brazil.

2. Universidade de Brasília, Brasília, DF, Brazil.

\section{ABSTRACT}

Objective: To evaluate the correlation between knee axis and hindfoot axis in patients with advanced gonarthrosis, and the association between ankle function and angular deformities. Methods: 72 patients were enrolled in the study: $66 \%$ were women, and mean age was 58.7 years. The anatomical axis of the knee and hindfoot were measured by short knee radiographs and long axial view of the hindfoot. Results: Among the study group, $79.2 \%$ presented varus knee (mean $15^{\circ} \pm 7.69^{\circ}$ ) and $20.8 \%$ valgus (mean $15.9^{\circ} \pm 7.7^{\circ}$ ). $63.9 \%$ had hindfoot varus (mean $8.5^{\circ} \pm 6.07^{\circ}$ ) and $36.1 \%$ valgus $\left(\right.$ mean $\left.3.9^{\circ} \pm 3.92^{\circ}\right)(p<0.05)$. The mean value for the American Orthopaedic Foot and Ankle Society (AOFAS) score was 74.26 points, and values were significantly higher among patients with hindfoot varus $(p<0.05)$. We found no correlation between gender or AOFAS score and knee and hindfoot axes, nor between deformities in the knee and hindfoot axes ( $p>0.05)$. The subgroup genu valgum hindfoot varus presented a moderate correlation ( $r=0.564 ; p<0.05)$. Conclusion: We found no association between the anatomical axes of the knee and hindfoot. Patients with gonarthrosis and hindfoot varus presented a better ankle function. Level of Evidence II, Prognostic Studies - Investigating the Effect of a Patient Characteristic on the Outcome of Disease.

Keywords: Ankle Joint. Arthroplasty, Replacement, Knee. Radiography. Osteoarthritis, Knee.

\section{RESUMO}

Objetivo: Avaliar a correlação entre o eixo do joelho e o eixo do retropé em pacientes com gonartrose avançada, e a relação da função do tornozelo com as deformidades angulares. Métodos: 72 pacientes, sendo 66\% mulheres, idade média 58,7 anos participaram do estudo. Mediu-se o eixo anatômico do joelho e do retropé por meio de radiografias curtas dos joelhos e a incidência axial longa do retropé. Resultados: da amostra, 79,2\% apresentavam eixo do joelho em varo (média $15^{\circ} \pm 7,69^{\circ}$ ) e 20,8\% valgo (média 15,9 $\pm 7,7^{\circ}$ ). 63,9\% retropé varo (média $8,5^{\circ} \pm 6,07^{\circ}$ ) e 36,1\% valgo (média 3,9० $\pm 3,92^{\circ}$ ) $(p<0,05)$. O valor médio do escore AOFAS foi 74,26 pontos, com valores significativamente maiores nos pacientes com retropé varo $(p<0,05)$. Não houve correlação entre o sexo ou o escore AOFAS e os eixos do retropé e do joelho, ou entre desvios no eixo do joelho e os desvios no eixo do retropé $(p>0,05)$. Observou-se uma associação moderada no subgrupo genuvalgo - retropé varo $(r=0,564 ; p<0,05)$. Conclusão: Não houve associação entre os eixos anatômicos do joelho e do retropé. Pacientes com gonartrose e retropé varo apresentaram melhor função do tornozelo. Nível de Evidência II, Estudos prognósticos - Investigação do efeito de característica de um paciente sobre o desfecho da doença.

Descritores: Articulação do Tornozelo. Artroplastia do Joelho. Radiografia. Osteoartrite do Joelho.

Citation: Mansur H, Rocha FA, Souza Filho PGT, Castro IM Jr. Relationship between the knee and hindfoot axes in patients with severe knee osteoarthritis. Acta Ortop Bras. [online]. 2020;28(5):229-232. Available from URL: http://www.scielo.br/aob.

\section{INTRODUCTION}

Approximately 300,000 total knee arthroplasties (TKA) are performed annually in the United States only. ${ }^{1}$ TKA has proven to be a safe surgery with high success rates, improving patients' quality of life, and being increasingly indicated. ${ }^{2-4}$ Some factors may affect TKA success, such as: age below 55 years, male gender, obesity, and presence of comorbidities. ${ }^{1,4-6}$ The correlation between knee and hindfoot alignment is yet to be fully elucidated. ${ }^{7-10}$ For Norton et al., ${ }^{11}$

All authors declare no potential conflict of interest related to this article.

The study was conducted at Instituto Nacional de Traumatologia e Ortopedia.

Correspondence: Henrique Mansur. Área Militar do Aeroporto Internacional de Brasília, Brasília, DF, Brasil, 71607-900. henrimansur@globo.com 
understanding the compensatory mechanisms between these joints would help guiding deformity correction during TKA.

Some authors have reported an association between genu varum and hindfoot valgus, as well as between genu valgum and hindfoot varus, especially among individuals without subtalar joint involvement. ${ }^{11-14}$ Although it is unclear how the hindfoot and ankle joints compensate knee deformity, varus deformity of the knee is believed to promote a deviation of the subtalar in eversion and valgus. ${ }^{10,14-16}$ In this sense, some studies reported an improvement in preoperative hindfoot valgus deformity after femorotibial joint realignment in patients with genu varum submitted to TKA. ${ }^{10,12,13,17}$ A study also reported that nearly $60 \%$ of patients with advanced gonarthrosis complained about foot pain before TKA and none of them exhibited radiographic evidence of ankle or subtalar arthrosis, what suggests that these pains were caused by deformities in the midfoot and hindfoot. Although the author has related foot and ankle pain in patients in preoperative TKA, he did not evaluate the function of the hindfoot and ankle within the sample. ${ }^{18}$

Understanding the compensatory association between knee and hindfoot alignment is important, especially among patients with advanced and symptomatic osteoarthritis with indication for TKA. ${ }^{10}$ Associated with the evaluation of ankle function in these patients and its correlation with hindfoot and knee axes, this mechanism will play a key role in managing this deformity and planning its surgery. This study aimed to analyze the correlation between the knee joint and hindfoot axes to evaluate the ankle/hindfoot function in patients with advanced gonarthrosis.

\section{MATERIALS AND METHODS}

This study was approved by the Research Ethics Committee of the institution, and all participants signed an Informed Consent Form. This is a cross-sectional study conducted in 2015, composed of patients with advanced arthrosis with indication for TKA. Patients who failed in performing the requested imaging tests or disagreed to participate were excluded of this study.

The characteristics recorded were gender, age at the time of the surgery, and affected foot. The anatomical axis of the knee and hindfoot were measured by radiographs. The function and pain in the hindfoot were quantified using the American Orthopaedic Foot and Ankle Society (AOFAS) scale for ankle and hindfoot, translated to Portuguese. ${ }^{19}$ This scale is composed of nine items summing a maximum score of 100 , among which 50 points refer to function, 40 to pain, and 10 to joint alignment.

Patients were separated into subgroups according to the anatomical axis of the knee - genu varum and genu valgum - and hindfoot axis - varus or valgus. Demographic characteristics, AOFAS score, and radiographic parameters were compared among subgroups.

\section{Radiographic Analysis}

The anatomical axis of the femorotibial joint was measured by short knee radiographs in anteroposterior (AP) and profile, all with bipodalic support, maximum knee extension, and patellae facing forward. The anatomical axis of the knee was measured using two points in the femur: one in the center of the intercondylar fossa and another $10 \mathrm{~cm}$ proximal to the first, at the midpoint between the two outside cortical regions. Regarding the tibia, the points were set in the center of the tibial eminence and $10 \mathrm{~cm}$ distal, at the midpoint between the two outside cortical regions. After tracing lines that connected the points in the femur and tibia, their intersection represented the anatomical axis or femorotibial angle (FTA). ${ }^{20}$

For long axial view of the hindfoot, patients stood over the film in a plain bipodalic support and were imaged in the posteroanterior and craniocaudal direction under a $45^{\circ}$ caudal angulation, $100 \mathrm{~cm}$ apart from the hindfoot. The film was positioned perpendicular to the central axis of the radiation beam (Figure 1). The hindfoot axis was calculated by the angle between two line: one representing the leg load-bearing axis and another representing the calcaneal axis. The load-bearing axis was represented by the longitudinal tibial axis, by bisecting the tibia into two diaphyseal points 10 and $15 \mathrm{~cm}$ proximal to the tibial pilon. The calcaneal axis was identified by bisecting the calcaneus into two points. These values were considered positive when the load-bearing axis was medial to the lowest point in the calcaneus (valgus axis) and negative when lateral (varus axis) (Figure 2). ${ }^{21.22}$ In a normal radiograph of an aligned hindfoot, the calcaneal axis should be parallel to the longitudinal axis of the tibia $\left(0^{\circ}\right)$, although located 5-10 mm lateral to the tibial axis. Angular values of up to $1^{\circ}$ for varus or valgus are considered ideal. ${ }^{23}$

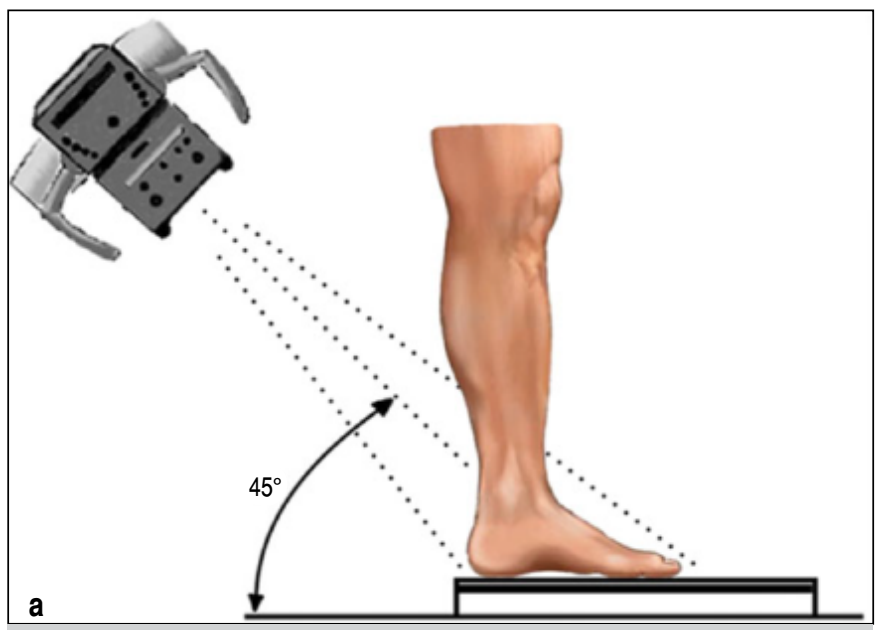

Figure 1. Illustration of patient positioning for long axial view of the hindfoot. $^{15}$
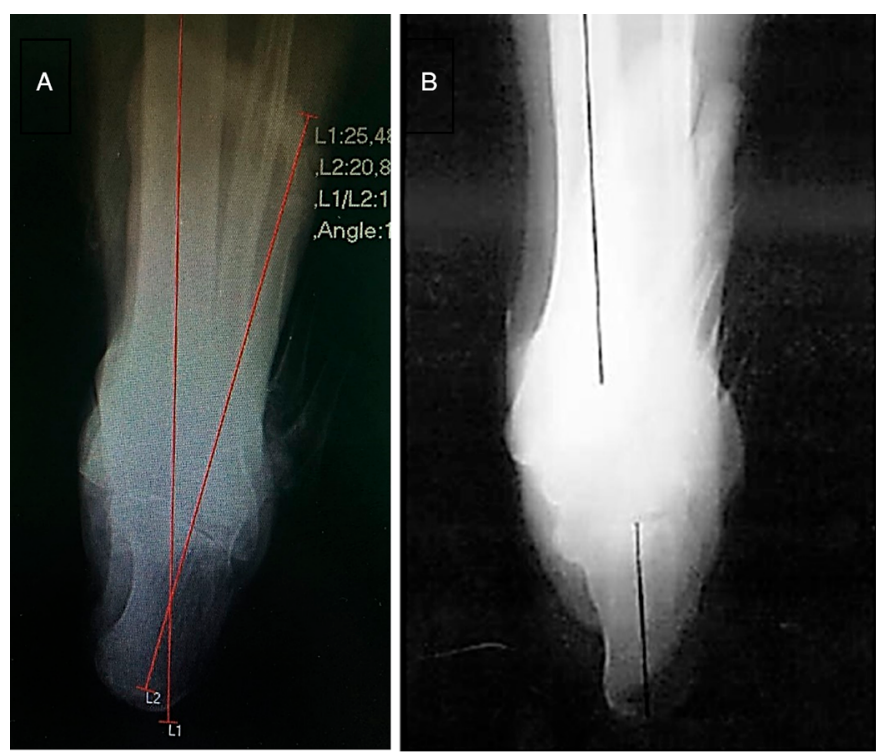

Figure 2. A: long axial view of the hindfoot, with hindfoot axis measure; B: illustration of hindfoot axis measurement in the long axial view of the hindfoot. ${ }^{22}$

A Shimadzu X-ray device, rated at $50 \mathrm{kV}$ and $40 \mathrm{~mA}$, was used. Angulations were determined using the $\mathrm{DICOM}^{\circledR}$ digital application. To ensure a greater reliability of angulations, scans were evaluated by two foot and ankle surgeons of the institution. 


\section{Statistical Analysis}

Descriptive data analysis consisted of graphs construction, frequency distributions, and calculation of descriptive statistics (proportions of interest for all variables and calculation of minimum, maximum, mean, and standard deviation). Kolmogorov-Smirnov (KS) and Shapiro-Wilk (SW) tests were used to assess normality of the continuous variables. When unpaired measures of the same variable showed normality, Student's t-test was used to compare them. When they did not follow normal distribution, the Mann-Whitney's nonparametric test was used. The relationship between two quantitative variables was determined by calculating Spearman's or Pearson's rank correlation coefficient. Chi-Square test was used to verify a significant association between two qualitative variables. A database was built in a Microsoft Excel 2011 spreadsheet to analyze collected data using IBM SPSS (Statistical Package for the Social Science) version 21.0. All discussions considered a maximum significance level of 5\% (0.05).

\section{RESULTS}

A total of 72 patients met the inclusion and exclusion criteria, among which women (66.7\%) and left-foot affectation (56.9\%) were predominant. The mean age was $58.7 \pm 10,67$ years.

Fifteen patients (20.8\%) presented valgus deformity in the knee and 57 patients (79.2\%) varus deformity. These proportions had a significant difference ( $p$-value $<0.05)$. We observed that valgus knee had a mean of $15.9^{\circ}\left(\mathrm{SD} \pm 7.7^{\circ}\right)$ and varus knee of $15^{\circ}\left(\mathrm{SD} \pm 7.69^{\circ}\right)$, with no statistically significant difference $(p>0.05)$. Of the total sample, 26 patients presented hindfoot valgus (36.1\%), with mean angular value of $3.98^{\circ}$, and 46 varus (63.9\%), with mean angular value of $8.52^{\circ}$. This difference was statistically significant $(p=0)$. The mean value for the American Orthopaedic Foot and Ankle Society (AOFAS) score was 74.26 points, ranging from 40 to 97 points. We found a statistically significant difference $(p=0.01)$ when analyzing scores by hindfoot axis, with higher values among patients with hindfoot varus, but not by knee axis $(p>0.05)$ (Table 1).

Table 1. Mean values of the overall AOFAS score and by hindfoot and knee axes.

\begin{tabular}{c|c|c|c|c|c}
\hline \multicolumn{6}{c}{ AOFAS score } \\
\hline \multirow{2}{*}{ Overall } & Axis & $\mathbf{n}(\%)$ & Mean & SD & p-value \\
\hline \multirow{2}{*}{ Hindfoot } & & 72 & 74.26 & 13 & \\
\cline { 2 - 6 } & Varus & 63.9 & 77.41 & 11.70 & \multirow{2}{*}{$\mathrm{p}=0.01(\mathrm{MW})$} \\
\cline { 2 - 5 } Knee & Valgus & 36.1 & 68.69 & 13.53 & \\
\cline { 2 - 5 } & Varus & 79.2 & 75.49 & 12.64 & \multirow{2}{*}{$\mathrm{p}>0.05(\mathrm{TT})$} \\
\cline { 2 - 5 } & Valgus & 20.8 & 69.60 & 13.73 & \\
\hline
\end{tabular}

SD: standard deviation; MW: Mann-Whitney's test; TT: T-test.

We found no correlation between gender and hindfoot and knee axis (both with $p>0.05$ in Chi-Square Test). The correlation between the knee and hindfoot axes presented no statistical significance, i.e., we found no association between knee axis deformity and hindfoot axis deformity $(p>0.05)$. We also found no correlation between the knee and hindfoot axes and the AOFAS score $(p>0.05)$. In assessing the correlation between the knee and hindfoot axis for each subgroup (varus knee - hindfoot varus; varus knee - hindfoot valgus; valgus knee - hindfoot varus; and valgus knee - hindfoot valgus), we observed a moderate association in the genu valgum hindfoot varus subgroup ( $r=0.564 ; p<0.05$ Spearman's Rho).

\section{DISCUSSION}

The axes of the lower limb may be affected by deformities involving the hip, knee, and ankle joints. Deformities that occur in one of these joints are believed to cause compensatory changes in the others. However, such mechanisms are still unclear. ${ }^{7,8,10,11}$

Our study evaluated: (1) the presence of hindfoot deformity in patients with advanced knee osteoarthritis and the association between the knee and hindfoot axis; and (2) the ankle/hindfoot function in patients with advanced gonarthrosis, considering the knee and hindfoot axis. Our results indicate no association between the knee and hindfoot axes, except for a moderate association in the genu valgum - hindfoot varus subgroup. We also found no correlation between the ankle/hindfoot function and the knee and hindfoot axes. However, patients with hindfoot varus presented significantly higher values in the functional scale $(p<0.05)$.

Some studies have already verified the correlation between the hindfoot and ankle alignment but achieved conflicting results. Corroborating our findings, Chandler et al. ${ }^{12}$ and Mullaji et al. ${ }^{13}$ found no preoperative correlation between the alignment of the knee and hindfoot axes. In turn, Norton et al. ${ }^{11}$ observed an association between valgus knee deformity and hindfoot varus, and varus knee and hindfoot valgus. However, such association was not observed in patients with mild deformities (lower than 10\%) in the knee axis. ${ }^{11}$ Another study, conducted with patients with rheumatoid arthritis, found a moderate correlation between femorotibial and tibial-calcaneal angles, especially among patients with little subtalar joint involvement. ${ }^{10}$

We found no significant correlation between the foot and ankle axes. However, $86.6 \%$ of the patients with genu valgum presented hindfoot varus, and $92.3 \%$ of the patients with hindfoot valgus presented varus knee. This is a key information to understand the lower limb compensatory mechanisms, particularly the adaptive capacity of the subtalar joint. ${ }^{10}$ Clinically, for knee specialists, patients with advanced gonarthrosis and foot pain may benefit from the use of insoles until surgical correction of the knee axis is performed. As for foot and ankle surgeons, patients with knee deformities, hindfoot deviations, and acutely symptomatic feet that require surgical treatment must have hindfoot axis correction carefully planned to avoid hypercorrection in case an axial realignment is later performed on the knee.

Unlike previous studies, we subdivided patients into four groups (genu varum - hindfoot varus; genu varum - hindfoot valgus; genu valgum - hindfoot varus; and genu valgum - hindfoot valgus) to better understand the association between these lower limb axes. The only subgroup to present a significant correlation was genu valgum - hindfoot varus $(p<0.05)$. This might be explained because the subtalar joint is responsible for most of the hindfoot compensatory mechanism, in which the ankle play a small role. ${ }^{11}$ As the mobility of the talocalcaneal joint ranges from $25-30^{\circ}$ in inversion and $5-10^{\circ}$ in eversion, ${ }^{24}$ patients with genu valgum demand a greater subtalar compensation. Such mechanism was equally observed in patients with tibiotarsal arthrosis, in which the subtalar joint plays a key role in compensating the deformity and delaying the degenerative process. ${ }^{25}$

We found no other articles in the literature addressing ankle/hindfoot function association in patients with advanced knee osteoarthritis. Our study adopted the AOFAS scale to assess ankle/hindfoot function and obtained a final mean value of 74.26 points. We observed a significant difference $(p<0.05)$ in the scores of patients with hindfoot varus and valgus, with higher values in the first subgroup. However, the ankle function was not associated with the hindfoot or knee axis $(p>0.05)$. Elbaz et al. ${ }^{26}$ verified the association between gonarthrosis and Achilles tendon involvement by analyzing gait and applying two scores: Western Ontario and McMaster Osteoarthritis Index (WOMAC) and 36-item Short-Form (SF-36) Health Survey. Both scores, although validated, are not specific for assessing ankle/hindfoot function, and can be applied for any joint with osteoarthritis. A different study, 
conducted with patients submitted to TKA, analyzed the presence of foot pain in the preoperative and one-year postoperative. Among the 64 participants with advanced gonarthrosis, 59.4\% reported preoperative pain and none exhibited radiographic evidence of ankle or subtalar arthrosis. Radiographic improvement of the midfoot pronation was related to the reduced foot pain one year after the surgery, suggesting that deformities in the midfoot and hindfoot cause pain in patients with gonarthrosis. In the same study, nearly $70 \%$ of patients still reported foot pain after one-year postoperative. This group presented no improvement in radiographic parameters nor in various foot plantar pressure measures. ${ }^{18}$

Our study poses some limitations, such as using the short knee bipodalic radiography to measure knee axis. However, this radiographic method is supported by several studies in the literature. Kraus et al. ${ }^{27}$ evaluated 114 knee radiographs and compared the angles of anatomical axis measured by goniometer and $X$-ray in posteroanterior (PA) with flexed knee to the panoramic X-ray of the lower limb and found corresponding values without needing to use the higher cost examination. Another author ${ }^{28}$ analyzed the alignment and joint wear of 608 knees with arthrosis using anteroposterior (AP) orthostatic X-ray and concluded that such incidence enables the evaluation of the axis and degree of joint involvement.
Considering the importance of the subtalar joint in the compensatory mechanisms of lower limb deformities, the lack of an specific physical examination for its mobility and imaging exams to measure its axis were also regarded as limitations. As the AOFAS score covers pain and hindfoot alignment, we believe that pain and misalignment in patients with more severe joint involvement have possibly decreased their functional scores.

Further studies evaluating the subtalar joint axis and mobility and analyzing ankle pain and function in patients with knee arthrosis are necessary. Likewise, prospective studies evaluating hindfoot axis behavior in patients undergoing total knee arthroplasty are fundamental to better understand the compensatory mechanisms of the lower limbs.

\section{CONCLUSION}

Our results show a correlation between knee and hindfoot axes in patients with advanced gonarthrosis, particularly in the genu valgum - hindfoot varus subgroup. We also observed an association between the AOFAS scale values and the hindfoot axis, in which patients with gonarthrosis and hindfoot varus presented a better ankle function.

AUTHORS' CONTRIBUTIONS: Each author contributed individually and significantly to the development of this article. HM: wrote the article, participated in the review process, and approved the final version; FAR: conceived and planned activities that led to the study, wrote the article, and approved the final version; PGTSF: planned the activities that led to the study and wrote the article; IMCJ: participated in the review process and approved the final version.

\section{REFERENCES}

1. NIH Consensus Statement on Total Knee Replacement. NIH Consens State Sci Statements. 2003;20(1):1-34

2. Silva RR, Santos AAM, Carvalho JS Jr, Matos MA. Qualidade de vida após artroplastia total do joelho: revisão sistemática. Rev Bras Ortop. 2014;49(5):520-7.

3. Fernandes DA, Poeta LS, Martins CAQ, Lima F, Neto FR. Equilíbrio e qualidade de vida após artroplastia total de joelho. Rev Bras Ortop. 2018;53(6):747-53.

4. Kurtz S, Mowat F, Ong K, Chan N, Lau E, Halpern M. Prevalence of primary and revision total hip and knee arthroplasty in the United States from 1990 through 2002. J Bone Joint Surg Am. 2005;87(7):1487-97.

5. Mahomed NN, Barrett J, Katz JN, Baron JA, Wright J, Losina E. Epidemiology of total knee replacement in the United States Medicare population. J Bone Joint Surg Am. 2005;87(6):1222-8.

6. Kurtz S, Ong K, Lau E, Mowat F, Halpern M. Projections of primary and revision hip and knee arthroplasty in the United States from 2005 to 2030. J Bone Joint Surg Am. 2007;89(4):780-5.

7. Keenan MA, Peabody TD, Gronley JK, Perry J. Valgus deformities of the feet and characteristics of gait in patients who have rheumatoid arthritis. J Bone Joint Surg Am. 1991;73(2):237-47.

8. McLauren CAN, Wootton JR, Heath PD, Wynn Jones $\mathrm{CH}$. Pes planus after tibial osteotomy. Foot Ankle. 1989;9(6):300-3.

9. Teitge RA, MacMahon E. Osteoarthritis of the knee: concepts behind osteotomy. Semin Arthroplasty. 1996;7(2):114-23.

10. Nakada I, Nakamura I, Juji T, Ito K, Matsumoto T. Correlation between knee and hindfoot alignment in patients with rheumatoid arthritis: the effects of subtalar joint destruction. Mod Rheumatol. 2015;25(5):689-93.

11. Norton AA, Callaghan JJ, Amendola A, Phisitkul P, Wongsak S, Liu SS, et al. Correlation of knee and hindfoot deformities in advanced knee OA: compensatory hindfoot alignment and where it occurs. Clin Orthop Relat Res. 2015;473(1):166-74

12. Chandler JT, Moskal JT. Evaluation of knee and hindfoot alignment before and after total knee arthroplasty: a prospective analysis. J Arthroplasty. 2004;19(2):211-6.

13. Mullaji A, Shetty GM. Persistent hindfoot valgus causes lateral deviation of weightbearing axis after total knee arthroplasty. Clin Orthop Relat Res. 2011;469(4):1154-60.

14. Hayashi K, Tanaka Y, Kumai T, Sugimoto K, Takakura Y. Correlation of compensatory alignment of the subtalar joint to the progression of primary osteoarthritis of the ankle. Foot Ankle Int. 2008;29(4):400-6.

15. Reilingh ML, Beimers L, Tuijthof GJM, Stufkens SAS, Maas M, van Dijk CN. Measuring hindfoot alignment radiographically: the long axial view is more reliable than the hindfoot alignment view. Skeletal Radiol. 2010;39(11):1103-8.
16. Desai SS, Shetty GM, Song HR, Lee SH, Kim TY, Hur CY. Effect of foot deformity on conventional mechanical axis deviation and ground mechanical axis deviation during single leg stance and two leg stance in genu varum. Knee. 2007;14(6):452-7.

17. Hara Y, Ikoma K, Arai Y, Ohashi S, Maki M, Kubo T. Alteration of hindfoot alignment after total knee arthroplasty using a novel hindfoot alignment view. J Arthroplasty. 2015;30(1):126-9.

18. Saito I, Okada K, Wakasa M, Abeb H, Saito A. Foot pressure pattern, hindfoot deformities, and their associations with foot pain in individuals with advanced medial knee osteoarthritis. Gait Posture. 2018;59:83-8.

19. Rodrigues RC, Masiero D, Mizusaki JM, Imoto AM, Peccin MS, Cohen M, et al. Tradução, adaptação cultural e validação do "American Orthopaedic Foot and Ankle Society (AOFAS) Ankle-Hindfoot Scale". Acta Ortop Bras. 2008;16(2):107-11.

20. Matos LF, Giordano M, Cardoso GN, Farias RB, Albuquerque RP. Análise radiográfica comparativa do eixo anatômico na osteoartrite do joelho: avaliação inter e intraobservadores. Rev Bras Ortop. 2015;50(3):283-9.

21. Kleiger B, Mankin HJ. A roentgenographic study of development of the calcaneus by means of the posterior tangential view. J Bone Joint Surg Am. 1961;43(7):961-9.

22. Lamm BM, Mendicino RW, Catanzariti AR, Hillstrom HJ. Static rearfoot alignment: a comparison of clinical and radiographic measures. J Am Podiatr Med Assoc. 2005;95(1):26-33.

23. Mendicino RW, Catanzariti AR, Reeves CL, King GL. A systematic approach to evaluation of the rearfoot, ankle, and leg in reconstructive surgery. J Am Podiatr Med Assoc. 2005;95(1):2-12.

24. Sarrafian SK. Biomechanics of the subtalar joint complex. Clin Orthop Relat Res. 1993;(290):17-26

25. Krähenbühl N, Horn-Lang T, Hintermann B, Knupp M. The subtalar joint: a complex mechanism. EFORT Open Rev 2017;2(7):309-16.

26. Elbaz A, Magram-Flohr I, Segal G, Mor A, Debi R, Kalichman L. Association between knee osteoarthritis and functional changes in ankle joint and Achilles tendon. J Foot Ankle Surg. 2017;56(2):238-41.

27. Kraus VB, Vail TP, Worrel T, McDaniel G. A comparative assessment of alignment angle of the knee by radiographic and physical examination methods. Arthritis Rheum. 2005;52(6):1730-5

28. Khan FA, Koff MF, Noiseux NO, Bernhardt KA, O'Byrne MM, Larson DR, et al. Effect of local alignment on compartimental patterns of knee osteoarthritis. $J$ Bone Joint Surg Am. 2008;90(9):1961-9. 